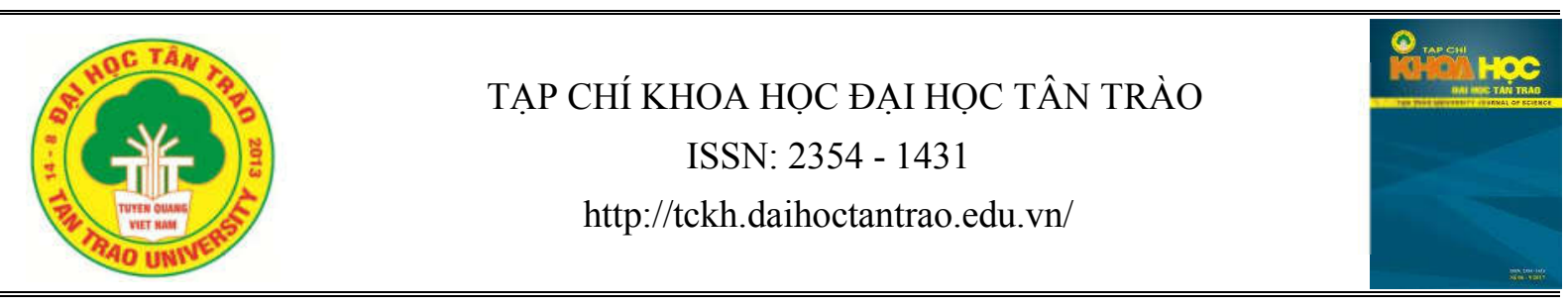

\title{
Nhu cầu về quyền của người dân tộc thiểu số trên địa bàn tỉnh Tuyên Quang hiện nay - lý luận và thực tiễn
}

\author{
Đỗ Mạc Ngân Doanh ${ }^{a}$ \\ ${ }^{a}$ Sở Khoa học và Công nghệ tỉnh Tuyên Quang
}

\section{Thông tin bài viết}

Ngày nhận bài:

28/4/2018

Ngày duyệt đăng:

$12 / 6 / 2018$

Tì khoá:

Quyền của ngườ dân tộc thiểu số, quyền con nguời, nhu cầu về quyền, ngưòi dân tộc thiểu số ở Tuyên Quang.

\section{Tóm tắt}

Tuyên Quang được đánh giá cao trong lĩnh vực bảo đảm thực thi các chính sách dân tộc và thúc đẩy đại đoàn kết dân tộc. Trong hướng đi hội nhập, tỉnh Tuyên Quang luôn nỗ lực góp phần thúc đẩy thực thi các cam kết quốc tế, tuân thủ Hiến pháp Việt Nam năm 2013, pháp luật Việt Nam hiện hành và định hướng bảo đảm quyền con người, quyền công dân trong nhà nước pháp quyền xã hội chủ nghĩa. Với tiếp cận chung của pháp luật về quyền con người, nhu cầu về quyền là những nội dung chính, cốt lõi nhất của quyền con người đối với chủ thể hưởng quyền tại một vị trí địa lý, vùng, khu vực, địa phương cụ thể. Bài viết sau sẽ làm sáng tỏ các nhu cầu đặc thù của người dân tộc thiểu số ở Tuyên Quang qua đó nhận diện được trạng thái của quyền và làm rõ được tính sát, hợp và hiệu quả của bảo đảm quyền của người dân tộc thiểu số ở Tuyên Quang hiện nay.

\section{Khái niệm và nội dung quyền của người dân tộc thiểu số}

Lý thuyết nghiên cứu tâm lý học dân tộc đã chỉ ra rằng ở những quốc gia đa dân tộc có sự khác biệt giữa các dân tộc về điều kiện địa lý, thành phần dân cư, cũng như các điều kiện chính trị, xã hội, kinh tế và văn hóa. Điều đó dẫn đến sự khác biệt về trình độ phát triển, mức độ bất bình đẳng về vị thế trong xã hội giữa các cộng đồng dân tộc. Và cũng là nguyên nhân chính dẫn đến sự khác nhau về nhu cầu bảo đảm quyền con người. Dưới góc độ thúc đẩy thực thi quyền con người, nhu cầu về quyền là xu hướng bộc lộ các dấu hiệu vi phạm hoặc thiếu thốn về điều kiện bảo đảm quyền trong một số nội dung nhất định. Tại một quốc gia có hệ thống đồ sộ với với khoảng 183 chính sách, được thể chế qua 264 văn bản [1], bao trùm toàn bộ đời sống chính trị, kinh tế, văn hóa và xã hội của người dân tộc thiểu số, cần phải có nghiên cứu lý luận và thực tiễn về nhu cầu về quyền để có biện pháp bảo đảm quyền con người ở mức độ hiệu quả nhất. Tuy nhiên, để xác định được các vấn đề/ nhu cầu/ nội dung đặc thù tại một vùng, địa phương cụ thể thì chúng ta cần phải nắm được nền tảng chung về quyền của người dân tộc thiểu số trên bình diện quốc tế và quốc gia.

Cho đến nay, khái niệm và nội hàm về quyền con người, quyền của người dân tộc thiểu số vẫn là những vấn đề pháp lý đòi hỏi phải liên tục hoàn thiện và phát triển. Nếu như cách hiểu về quyền con người thường được nhắc đến nhất với tư cách là những bảo đảm pháp lý phổ quát (universal legal guarantees), có tác dụng bảo vệ các cá nhân và các nhóm chống lại những hành động (actions) hoặc sự bỏ mặc (omissions) mà làm tổn hại đến nhân phẩm, những sự được phép (entitlements) và tự do cơ bản (fundamental freedoms) của con người, thì quyền của người dân tộc thiểu số hay các đối tượng dễ bị tổn thương (vulnerable groups) sẽ hướng đến: Các nhóm xã hội phải chịu những thiệt thòi và có xuất phát điểm thấp hơn xứng đáng và cần thiết được hưởng các quyền đặc thù (các quyền của nhóm) để có thể đạt được sự bình đẳng thực chất với các nhóm khác trong việc hưởng thụ các quyền con người [ ${ }^{3 ;}$ tr.15].

Trên bình diện quốc tế, có một thực tế đáng quan tâm là đến nay trong tất cả các văn kiện quốc tế về quyền con người của Liên hợp quốc đều không đưa ra được một khái niệm nào về "người thiểu số" hay 
"quyền của người thiểu số", bên cạnh đó "quyền của người thiểu số" cũng chưa được đặt trong một điều ước quốc tế hệ thống và riêng biệt, có giá trị ràng buộc pháp lí. QCNDTTS đã không được ghi nhận trong Tuyên ngôn nhân quyền của Liên hợp quốc năm 1948 với lý do: "Xét thấy rằng rất khó để có thể đura ra một giải pháp thống nhất cho vấn đề nhạy cảm và phí̛c tạp này, mà tại mỗi quốc gia nơi nó phát sinh lại có nhũng khía cạh đặc biệt khác nhau" [4]. Hiện nay, cơ sở pháp lý của vấn đề này được căn cứ theo hai điều khoản nằm trong hai công ước quốc tế cơ bản về quyền con người đó là Điều 27 ICCPR 1966 và Điều 30 CRC 1989. Bên cạnh đó năm 1992, Liên hợp quốc đã thông qua một Tuyên ngôn về quyền của các nhóm thiểu số về quốc tịch hoặc chủng tộc, tôn giáo và ngôn ngữ, tuy nhiên văn kiện này lại không có giá trị ràng buộc pháp lý và cũng không đưa ra khái niệm nào về chủ thể hưởng quyền cũng như không mở rộng nội hàm về quyền so với Điều 27 ICCPR.

Tại mỗi quốc gia đa dân tộc gắn với từng giai đoạn phát triển mà mỗi giai đoạn lại có cách định nghĩa khác nhau về quyền con người, quyền của người dân tộc thiểu số. Có thể đưa ra một định nghĩa phù hợp với nhu cầu bảo đảm quyền của người thiểu số tại các quốc gia đa dân tộc, mang tính chất tổng hợp và tương đối như sau: "Quyền của nguoời dân tộc thiểu số (QCNDTTS) là tập hợp những nhu cầu, lợi ich vốn có của mỗi cá nhân nguời dân tộc thiểu số trong mối tuoong quan với cộng đồng dân tộc đa số trong một quốc gia, được pháp luật của quốc gia đa dân tộc đó ghi nhận và bảo đảm thực hiện"l. Theo hướng đó, bảo đảm quyền của người dân tộc thiểu số ở các quốc gia đa dân tộc hiện nay bao gồm các nghĩa vụ bảo đảm, tôn trọng, bảo vệ và thúc đẩy thực hiện quyền lợi của mỗi cá nhân/cộng đồng nguoơi dân tộc thiểu số (NDTTS) của nhà nước, bằng tổng thể các biện pháp, xuất phát từ chính nhu cầu của các cá nhân/cộng đồng dân tộc trong quốc gia đa dân tộc, nhằm duy trì sự bình đẳng đối với tất cả các quyền con người trong hưởng thụ quyền, bảo vệ cá nhân/ cộng đồng NDTTS chống lại sự phân biệt đối xử và làm phong phú thêm sự đa dạng văn hóa và di sản của xã hội, bên cạnh đó thúc đẩy hòa bình, bảo đảm sự ổn định chính trị và xã hội.

Theo quy định của pháp luật quốc tế và hướng dẫn hiện hành của Văn phòng Cao ủy Nhân quyền Liên Hợp quốc (OHCHR) [6], để bảo đảm, tôn trọng, bảo

\footnotetext{
${ }^{1}$ Theo định nghĩa của TS. Đỗ Mạc Ngân Doanh, sử dụng trong Luận án về "Quyền của nguời dân tộc thiểu số ở Việt Nam hiện nay", Học viện Khoa học Xã hội, Viện hàn lâm khoa học xã hội Việt Nam, 2017.
}

vệ và thúc đẩy QCNDTTS, nghĩa vụ của các nhà nước đa dân tộc gắn chặt với các nội dung cốt lõi sau: $M o ̣ ̂ t$ là, bảo đảm, tôn trọng, bảo vệ và thúc đẩy bình đẳng và không phân biệt đối xử đối với tất cả các khía cạnh của quyền con người cho người dân tộc thiểu số, bao gồm: các quyền chính trị, dân sự, kinh tế, văn hóa và xã hội (theo các công ước quốc tế mà Việt Nam là thành viên). Hai là, bảo đảm một số quyền đặc thù, riêng có đối với nhóm thiểu số về dân tộc (căn cứ theo sự ghi nhận tại ICCPR 1966). Ba là, phải bảo đảm sụ cân bằng giữa các nhóm lợi ich, nhu cầu của các cộng đồng dân tộc ở các vùng miền khác nhau, giữa các nội dung quyền con nguời và các quyền đặc thù của ngưòi dân tộc thiểu số.

Để làm rõ hơn nội hàm và dẫn chiếu đến các nguồn của pháp luật quốc tế về nhân quyền (công ước quốc tế mà Việt Nam là thành viên), có thể đề cập đến các nội dung làm khung cơ bản như sau:

- Quyền bình đẳng, không phân biệt đối xử trong tiếp cận và thụ hưởng các $\mathrm{QCN}$;

- Nhóm quyền sống còn: hướng tới khía cạnh bảo đảm quyền có quốc tịch và quyền được xác định dân tộc; bảo đảm an ninh cá nhân đối với NDTTS và bảo đảm sự phát triển ổn định và quy mô dân số, bảo đảm quyền sống còn của trẻ em NDTTS;

- Nhóm quyền hưởng thụ và phát huy văn hóa, tín ngưỡng, truyền thống và tập quán của NDTTS;

- Nhóm quyền được sử dụng ngôn ngữ thiểu số;

- Nhóm quyền được tham gia hiệu quả;

- Nhóm quyền an sinh xã hội;

- Giới hạn quyền và căn cứ giới hạn quyền của người dân tộc thiểu số nhằm bảo vệ các quyền tự do hợp pháp và $\mathrm{QCN}$ của người khác; bảo vệ an ninh quốc gia (national security); bảo đảm an toàn cho cộng đồng (public safety); bảo vệ sức khỏe hay đạo đức của cộng đồng (public health or moral).

2. Nhu cầu về quyền của người dân tộc thiểu số ở một số điểm khảo sát trên địa bàn tỉnh Tuyên Quang hiện nay trong mối liên hệ với các nội dung của quyền con người

Thực trạng kinh tế, văn hóa, xã hội của NDTTS ở Việt Nam nói chung là nội dung đã được quan tâm nghiên cứu và thống kê thực tiễn khá đầy đủ. Qua đó, phản ánh thực tiễn hiện nay về những thực trạng của việc thực hiện các QCNDTTS và thực trạng của các điều kiện bảo đảm QCNDTTS, đặc biệt là điều kiện về nguồn lực. Tuy nhiên, hầu như chưa có nghiên cứu nào đưa ra những đánh giá gắn với quyền con người của NDTTS, ví dụ như: quyền sống còn của trẻ em NDTTS; quyền tham 
gia - phản biện xã hội; quyền tiếp cận thông tin... và các QCN khác. Cũng như vậy, tại tỉnh Tuyên Quang, chưa có một nghiên cứu hệ thống nào đánh giá về thực trạng pháp lý về quyền của người dân tộc thiểu số, về các nội dung quyền bị xâm hại.

Do đó, trong điều kiện cho phép, nhóm đề tài đã tiến hành thực hiện khảo sát 800 phiếu hỏi và 160 phiếu khảo sát lại tại các huyện, thành phố là nơi sinh sống tập trung của một số cộng đồng người dân tộc thiểu số (đối tượng dễ bị tổn thương) ở Tuyên Quang. Trong đó, mỗi điểm lựa chọn đều gắn với những tiêu chí nhất định, cụ thể là: Điểm khảo sát có điều kiện kinh tế - xã hội khá, đi lại thuận tiện (Sơn Dương); Điểm khảo sát có điều kiện kinh tế - xã hội khó khăn (Hàm Yên); Điểm khảo sát có điều kiện kinh tế - xã hội và đi lại rất khó khăn (Na Hang); Điểm khảo sát tập trung các đối tượng có bệnh huyết tán là người dân tộc thiểu số được hưởng BHYT toàn phần (Bệnh viện tỉnh Tuyên Quang); Điểm khảo sát tập trung các đối tượng di dân tái định cư được hưởng chính sách cấp nhà và đất (thôn 24 , xã Kim Phú - Yên Sơn). Kết quả cho thấy các nhóm nhu cầu về quyền là tương đối đồng đều, không có sự phân tán lớn về nhu cầu hưởng quyền. So với các nghiên cứu khác của chúng tôi ở địa phương khác trên cả nước, có thể nhận định, trình độ nhận thức của bà con người dân tộc thiểu số ở Tuyên Quang có sự vượt trội hơn so với một số vùng miền có tính đặc thù về dân tộc thiểu số ở Tây Nguyên, vùng núi và duyên hải miền Trung (Thanh Hóa, Nghệ An). Do đó, người dân tộc thiểu số ở Tuyên Quang có xu hướng hiểu biết toàn diện hơn về quyền con người và ngày càng hướng đến những vấn đề bậc cao của quyền (như văn hóa, y tế, tiếp cận thông tin, giáo dục...) chứ không chỉ đề cập đến những vấn đề bậc thấp của quyền (ăn, mặc, ở...).

Mặc dù vậy, do là một tỉnh miền núi, địa hình chia cắt, đời sống của bà con vùng sâu, vùng xa còn nhiều khó khăn nên những nội dung cơ bản về điều kiện sống tối thiểu, điều kiện giáo dục và lao động vẫn chiếm số lượng đáng kể.

Biểu đồ 1. Các nhu cầu về quyền của người dân tộc thiểu số tại các khu vực khảo sát của đề tài [7]

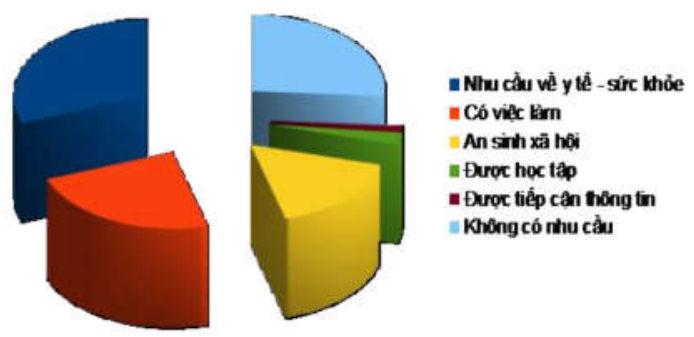

Nhóm nhu cầu được đề cập đến hàng đầu là vấn đề được khám chữa bệnh miễn phí, được cấp thẻ bảo hiểm y tế (quyền tiếp cận $\mathrm{y}$ tế). Đồng bào người dân tộc thiểu số ngày càng ý thức được tầm quan trọng của việc khám chữa bệnh. Hiện nay, hầu hết các cơ sở $\mathrm{y}$ tế/khám chữa bệnh gần nhất với nơi cư trú của gia đình tại khu vực khảo sát đều cách dưới 2 km đổ lại. Tuy nhiên, các cơ sở này đôi khi không thể đáp ứng nhu cầu của người dân tộc thiểu số, đặc biệt là giải quyết các bệnh nan $\mathrm{y}$, đòi hỏi tay nghề cao của $\mathrm{y}$ - bác sĩ và chi phí đắt đỏ.

Nhóm nhu cầu thứ hai liên quan đến vấn đề sinh kế của người dân tộc thiểu số ở Tuyên Quang (quyền an sinh xã hội, quyền về kinh tế). Theo số liệu điều tra, sinh kế (nghề nghiệp kiếm sống) chủ yếu của gia đình người dân tộc thiểu số là làm nông (65\%); 36\% là lao động chân tay còn lại có một số ít làm buôn bán, tự cung tự cấp hoặc nghề nghiệp khác. Nhu cầu có điều kiện để phát triển nông nghiệp ở vùng dân tộc thiểu số ở Tuyên Quang vẫn chiếm đa số. Hầu hết đồng bào đều được tuyên truyền về chính sách cho vay của Nhà nước theo Quyết định số 54/2012/QĐ-TTg ngày 4/12/2012 về việc Ban hành chính sách cho vay vốn phát triển sản xuất đối với hộ dân tộc thiểu số đặc biệt khó khăn giai đoạn 2012 2015. Có khoảng $1 / 3$ số người được hỏi có ý thức tiếp cận nguồn vốn này và được Nhà nước hỗ trợ giống lúa, ngô (hoặc cây trồng khác) để phát triển sản xuất theo Chương trình 135 .

Nhóm nhu cầu thứ ba là quyền được giáo dục. Hiện nay, phổ cập giáo dục tiểu học được thực hiện $100 \%$ tại địa bàn khảo sát, hầu hết không có trẻ em nào đang không được đến trường học. Tuy nhiên, vẫn có $1 / 3$ số người chỉ tham gia giáo dục hết bậc tiểu học, đặc biệt là các đối tượng tổn thương kép như: phụ nữ, người khuyết tật, người già... là người dân tộc thiểu số sinh sống ở vùng có điều kiện kinh tế - xã hội khó khăn. Thực tế khảo sát cho thấy điều kiện vật chất các trường cấp 1 điểm thôn còn thiếu thốn, tình trạng dột nát, thiếu bàn ghế, bảng để học vẫn diễn ra.

Nhóm thứ tư là nhu cầu về quyền được tiếp cận thông tin. Đây là nhóm nhu cầu mới, hiếm khi được đề cập đến ở vùng dân tộc thiểu số trên cả nước, bởi nhóm này bộc lộ ý thức tự chủ cao về kinh tế, văn hóa, xã hội, cũng là yếu tố cốt lõi của vấn đề phát triển. Tuyên Quang là tỉnh mà nhóm nhu cầu này được nhắc đến. Tuy nhiên, do hiệu quả phổ biến chính sách, pháp luật nhìn chung là chưa cao dẫn đến việc bà con người 
dân tộc thiểu số không nắm được đầy đủ các chính sách, pháp luật bảo vệ quyền con người của mình.

Qua nghiên cứu lý thuyết và thực tiễn điều tra, chúng tôi phát hiện ra những vấn đề nổi trội nhưng lại không được bà con người dân tộc thiểu số nhắc đến. Đó là: Quyền được xác định dân tộc, quyền sống còn, quyền bảo vệ ngôn ngữ thiểu số, quyền tham gia hiệu quả (tham gia ý kiến, xây dựng chính sách, pháp luật).

3. Đánh giá hiệu quả của khảo sát lại và tính ưu việt của sử dụng phương pháp của tiếp cận dựa trên quyền

Năm 2018, để đánh giá hiệu quả của công tác tuyên truyền Hiến pháp Việt Nam năm 2013 và sử dụng phương pháp của tiếp cận dựa trên quyền (human rights-based approach) của nghiên cứu, chúng tôi đã tiến hành thực hiện làm 160 phiếu hỏi xác xuất với chính những đối tượng cũ. Những thành công và tín hiệu đáng mừng mà chúng tôi nhận được khi tiến hành khảo sát lại về nhu cầu bảo đảm quyền của người dân tộc thiểu số thể hiện ở sự biến động kết quả khảo sát. Bao gồm cả về nhận thức đúng đắn, sự hưởng ứng nhiệt liệt và tăng đáng kể về các đề đạt, nguyện vọng của người dân tộc thiểu số... những nhân tố tích cực thúc đẩy nhóm "quyền tham gia" - quyền có chức năng tạo cơ hội cho các quyền con người khác.

Sau hơn một năm tiến hành khảo sát kết hợp tuyên truyền Hiến pháp năm 2013, nhận thức của bà con người dân tộc thiểu số cải thiện đáng kể. Cụ thể là hầu hết người được hỏi $(98,1 \%)$ đều cho câu trả lời chính xác về cách hiểu về bản chất của quyền con người, quyền công dân (lần 1 chỉ có $58,5 \%$ ). Với việc sử dụng các câu hỏi đóng, trực tiếp tuyên truyền các nội dung của quyền, chúng tôi nhận thấy người dân tộc thiểu số đều đã đưa ra quan điểm rõ ràng về các vấn đề như: 90,6\% biết hôn nhân cận huyết (lấy người có quan hệ họ hàng gần gũi về huyết thống) sẽ khiến trẻ em sinh ra trong gia đình có thể bị dị tật hoặc mắc các bệnh nan y (như bệnh máu không đông/huyết tán); 91,8\% biết rằng lấy vợ lấy chồng trước tuổi (tảo hôn) là vi phạm Hiến pháp và pháp luật; $81,3 \%$ biết về bảo hiểm y tế miễn phí và chính sách khám bệnh miễn phí cho người dân tộc thiểu số (ở vùng có điều kiện kinh tế khó khăn); 91,3\% người biết rằng Việt Nam là một trong những quốc gia có nhiều chính sách bảo vệ quyền của người dân tộc thiểu số nhất; $86,3 \%$ nghĩ rằng nghề thủ công hoặc việc làm ra các đặc sản, tạo ra khu du lịch văn hóa tại vùng dân tộc thiểu số cần được phát huy; 96,9\% người dân được hỏi cho rằng việc bảo tồn ngôn ngữ và giá trị văn hóa thiểu số là rất cần thiết; 97,5\% người dân ý thức được là quyền và nghĩa vụ của công dân đóng góp rất lớn vào sự phát triển cộng đồng, quốc gia - dân tộc.

Sự đa dạng của nhu cầu về quyền là điểm khác biệt lớn nhất mà chúng tôi nhận thấy. Trong đó, mối quan tâm của người dân tộc thiểu số trước hết vẫn là các nhu cầu cơ bản về $\mathrm{y}$ tế, sức khỏe, kinh tế, môi trường sống, điều kiện nhà ở, điện nước, quyền học tập, quyền có việc làm... sau đó mới tới các nhu cầu bậc cao về tiếp cận thông tin, an ninh con người, xây dựng môi trường xanh sạch đẹp, bảo tồn văn hóa thiểu số, cải cách hành chính...

\section{Biểu đồ 2. Khảo sát lại các nhu cầu về quyền của người dân tộc thiểu số [8]}

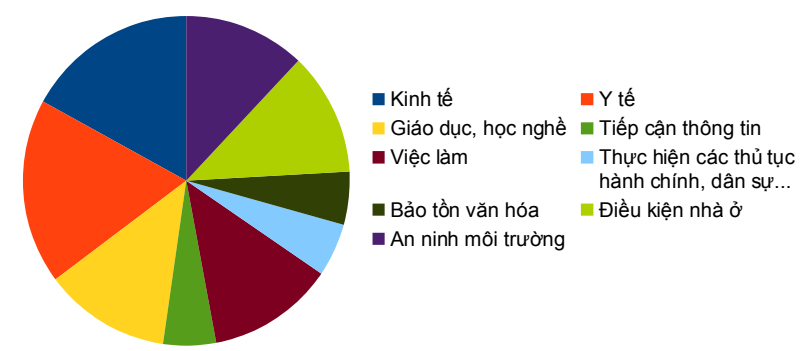

Điểm sáng nằm ở sự phân luồng các nhóm nhu cầu, người dân tộc thiểu số tại các điểm khảo sát không bỏ quên bất cứ nhóm nào, kể cả các vấn đề thuộc nhóm nhu cầu bậc cao được chúng tôi phát hiện (chưa được người dân quan tâm đến) ở lần trước. Nội dung các nhóm nhu cầu được người dân tộc thiểu số chỉ ra rất chi tiết, cụ thể, hướng tới các quyền con người về dân sự, chính trị, kinh tế, xã hội và văn hóa. Điều này càng chứng tỏ phương pháp tiếp cận của quyền con người là một tiếp cận hiệu quả ở vùng dân tộc thiểu số.

\section{4. Đánh giá trạng thái bảo đảm các nhóm nhu} cầu về quyền của người dân tộc thiểu số trên địa bàn tỉnh Tuyên Quang hiện nay

Lịch sử đã ghi nhận những thành tựu nổi bật của chính quyền và nhân dân Tuyên Quang về việc thực thi nhiều chính sách hiệu quả trên các lĩnh vực kinh tế, văn hóa, giáo dục, chính trị, quân sự, ngoại giao... nhằm củng cố khối đoàn kết dân tộc, nâng cao ý chí, sức mạnh toàn dân và đặc biệt là vai trò trong bảo vệ độc lập, chủ quyền lãnh thổ quốc gia - dân tộc (nation). Đó là những bài học kinh nghiệm thực tiễn vô cùng quan trọng đối với nhu cầu xây dựng và tổ chức thực thi QCNDTTS trong nhà nước pháp quyền xã hội chủ nghĩa ở Việt Nam. Hiện 
nay, dưới định hướng của Đảng Cộng sản Việt Nam và Nhà nước cộng hòa xã hội chủ nghĩa Việt Nam, UBND tỉnh, HDND tỉnh và các cơ quan chức năng đã nỗ lực triển khai các chính sách dân tộc đúng đối tượng và kịp tiến độ.

Thứ nhất, tỉnh Tuyên Quang đã tập trung tạo các điều kiện bảo đảm quyền lao động và có việc làm cho người dân tộc thiểu số. Bằng nguồn vốn đầu tư của Chương trình 135, từ năm 2011 đến 2016, tỉnh đã phân bổ trên 534 tỷ đồng, trong đó tập trung chủ yếu vào đầu tư xây dựng cơ sở hạ tầng thiết yếu cho các xã, thôn bản đặc biệt khó khăn, xã ATK; hỗ trợ phát triển sản xuất, xây dựng các mô hình sản xuất trồng cây nông nghiệp có năng xuất cao, từng bước thay đổi tập quán sản xuất, chăn nuôi.

Thứ hai, bảo đảm quyền an sinh xã hội, đến nay $100 \%$ số xã, với 2.044/2096 thôn bản thị trấn, trên $97,83 \%$ hộ dân trên địa bàn tỉnh được sử dụng điện lưới quốc gia, 100\% xã, phường, thị trấn và $99,8 \%$ thôn, bản (2.092/2.096 thôn, bản) có đường ô tô đến trung tâm. Thực hiện phân bổ 48.081 triệu đồng để đầu tư 33 công trình nước sinh hoạt tập trung tại các thôn bản có đông đồng bào dân tộc thiểu số sinh sống có khó khăn về nước sinh hoạt. Từ năm 2006 đến tháng $6 / 2017$, đã di chuyển bố trí, sắp sếp ổn định dân cư theo hình thức xen ghép cho 2.156 hộ ra khỏi vùng thiên tai, nguy hiểm, vùng đặc biệt khó khăn, khu rừng phòng hộ, rừng đặc dụng với tổng kinh phí thực hiện 29.105 triệu đồng; đến nay các hộ di chuyển đã ổn định đời sống và yên tâm phát triển kinh tế nơi ở mới.

Thứ ba, về bảo đảm quyền bầu cử và tham gia quản lý nhà nước và xã hội, theo số liệu từ Hội đồng bầu cử Quốc gia nhiệm kỳ 2016 - 2021, để chuẩn bị cho bầu cử Đại biểu Quốc hội khóa XIV và đại biểu Hội đồng Nhân dân các cấp, tỷ lệ cử tri đi bầu cử trên địa bàn tỉnh Tuyên Quang đạt tỷ lệ cao hàng đầu cả nước: 99,74\%.

Thứ tư, về bảo đảm quyền được học tập, tỉnh đã triển khai thực hiện đầy đủ, nghiêm túc các chính sách hỗ trợ của Nhà nước đối với học sinh là người dân tộc thiểu số. Ví dụ như: Chính sách hỗ trợ gạo cho học sinh tại các trường ở khu vực có điều kiện kinh tế - xã hội đặc biệt khó khăn theo Quyết định số 36/2013/QĐ-TTg ngày 18/6/2013 của Thủ tướng Chính phủ: Từ năm 2013 đến 2015 có tổng số 39.271 lượt học sinh được hỗ trợ, kinh phí thực hiện 13.040 triệu đồng. Quyết định số 12/2013/QĐ-TTg ngày
24/1/2013 của Thủ tướng Chính phủ về hỗ trợ cho học sinh THPT ở vùng có điều kiện kinh tế xã hội đặc biệt khó khăn: Từ năm 2013 đến 2015, tỉnh đã hỗ trợ cho 23.623 lượt học sinh trung học phổ thông ở các xã đặc biệt khó khăn, tổng kinh phí đã thực hiện hỗ trợ là: 57.772 triệu đồng. Quyết định số 85/2010/QĐ-TTg ngày 21/12/2010 của Thủ tướng Chính phủ về Ban hành một số chính sách hỗ trợ học sinh bán trú và trường phổ thông dân tộc bán trú: Tổng kinh phí thực hiện: 55.956,16 triệu đồng; Thời gian thực hiện: 2011 2015; số đối tượng được thụ hưởng: 13.538 người. Chính sách quy định về miễn, giảm học phí, hỗ trợ chi phí học tập và cơ chế thu, sử dụng học phí đối với các cơ sở giáo dục thuộc hệ thống giáo dục quốc dân từ năm học 2010 - 2011 đến năm học 2014 - 2015 theo Nghị định số 49/2010/NĐ-CP ngày 14/5/2010 của Chính phủ... [9].

Thứ năm, quyền về sức khỏe được tỉnh đặc biệt quan tâm, thể hiện qua nhiều chế độ ưu đãi và chính sách hỗ trợ bằng bảo hiểm $\mathrm{y}$ tế dân tộc. Từ năm 2010-2015 đã thực hiện cấp cho 1.492.101 lượt thẻ bảo hiểm y tế cho người dân tộc thiểu số trên địa bàn toàn tỉnh; kinh phí thực hiện hỗ trợ là: 778.539,16 triệu đồng. Đến nay 141 xã, phường đã có trạm y tế với 705 giường bệnh, 06 bệnh viện đa khoa huyện và 3 bệnh viện đa khoa khu vực, 05 bệnh viện thuộc tuyến tỉnh với điều kiện cơ sở vật chất hiện có đã cơ bản đáp ứng yêu cầu chăm sóc sức khỏe cho nhân dân các dân tộc trên địa bàn tỉnh, bình quân có 7,7 bác sĩ/10.000 dân. Ủy ban nhân dân tỉnh Tuyên Quang cũng đã ban hành Kế hoạch số 71/KH-UBND ngày 25/9/2015 của Ủy ban nhân dân tỉnh về thực hiện Đề án "Giảm thiểu tình trạng tảo hôn và hôn nhân cận huyết thống trong vùng dân tộc thiểu số giai đoạn 2015-2025" và tiến hành lựa chọn 02 xã tại huyện Yên Sơn, để xây dựng mô hình điểm thực hiện Đề án "Giảm thiểu tình trạng tảo hôn và hôn nhân cận huyết thống trong vùng dân tộc thiểu số".

Thứ sáu, thực thi nhóm quyền tự do và tham gia, người dân tộc thiểu số ở các địa bàn được khảo sát được bảo đảm toàn diện các khía cạnh của quyền như: tự do hội họp, quyền bầu cử, ứng cử, tiếp cận thông tin...

Thứ bảy, về bảo đảm quyền tiếp cận thông tin, hoạt động trợ giúp pháp lý bằng tiếng Kinh hoặc tiếng thiểu số đối với NDTTS được thực hiện theo kế hoạch.

Thứ tám, về thực thi quyền bảo tồn văn hóa, bản sắc của các cộng đồng dân tộc thiểu số trên địa bàn tỉnh. Nhiều dự án về sưu tầm, tư liệu hoá di sản văn 
hoá được thực hiện, hoàn thành kiểm kê di sản văn hóa phi vật thể trên địa bàn tỉnh đối với 15/26 dân tộc, gồm: Dân tộc Kinh, Tày, Dao, Mông, Sán Chay, Nùng, Sán Dìu, La Chí, Pà Thẻn, Cờ Lao, Ngái, Mường, Giáy, Pu Péo, Hoa và 01 nhóm người Thủy.

Tại mỗi vùng/ địa phương ở Việt Nam, các cộng đồng người dân tộc thiểu số có những đặc thù khác nhau về nhu cầu hưởng quyền (mối quan tâm đặc biệt hơn). Ví dụ như các tỉnh Tây Nam Bộ đặc biệt quan tâm đến vấn đề ngôn ngữ thiểu số, các tỉnh Tây Nguyên hướng đến bảo đảm an ninh cá nhân, an sinh xã hội, các tỉnh duyên hải và ven biển miền Trung như Thanh Hóa, Nghệ An lại chú ý đến quyền văn hóa và sống còn của các nhóm dân tộc rất ít người (Tà Ôi, Chứt...). Tỉnh Tuyên Quang hiện nay với điều kiện cơ sở vật chất ngày càng được cải thiện, phương tiện giao thông tới thủ đô Hà Nội thuận tiện hơn, đồng bào người dân tộc thiểu số sinh sống trên địa bàn tỉnh được tiếp cận với các quyền con người một cách đa diện và đầy đủ. Nghiên cứu thực tiễn đã hỗ trợ chúng tôi nhận diện với những mối quan tâm chính của bà con, đó là nhu cầu về quyền được phát triển kinh tế, các vấn đề của quyền về sức khỏe, khả năng tiếp cận thông tin và giáo dục. Qua đó, có thể nhận định chung, dưới góc độ thực thi quyền con người, việc triển khai thực hiện các chương trình, chính sách dân tộc ở Tuyên Quang góp phần bảo đảm toàn diện và sát hợp với nhu cầu của đồng bào người dân tộc thiểu số sinh sống trên địa bàn tỉnh. Trong thời gian tới, trên cơ sở những thành tựu đạt được, nhân dân và chính quyền địa phương ở Tuyên Quang cần nhận thức rõ và giải quyết tốt hơn các nhiệm vụ mới trên nhiều lĩnh vực tại vùng có đông người dân tộc thiểu số sinh sống nhằm phát triển bền vững, bảo đảm các quyền con người và tiếp tục tăng cường đại đoàn kết dân tộc./.

\section{TÀI LIÊUU THAM KHẢO}

1. Bế Thị Hồng Vân (2015), Báo cáo của Ủy ban dân tộc tại Hội thảo Liệu miền núi có cần tiến kịp miền xuôi ngày 17/10/2015, Army Hotel, Hà Nội;

2. Đỗ Mạc Ngân Doanh (2017), Quyền của nguời dân tộc thiểu số ở Việt Nam hiện nay, Luận án Tiến sĩ,
Học viện Khoa học Xã hội, Viện hàn lâm khoa học xã hội Việt Nam;

3. Khoa Luật - ĐHQGHN (2011), Luật quốc tế về quyền của các nhóm dễ bị tổn thuoong, Trung tâm nghiên cúu $Q C N$ và $Q C D, \mathrm{Nxb}$ Lao động Xã hội, Hà Nội;

4. Nghị quyết số $217 C$ (III) của Đại hội đồng Liên hơp quốc về viẹcc không đua vấn đề thiểu số vào UDHR 1948;

5. Hà Văn Ngạc (2017), Giải pháp phát triển kinh tế - xã hội vùng đồng bào dân tộc thiểu số trên địa bàn tỉnh Tuyên Quang, Hội thảo lần thứ 2 của Đề tài Một số giải pháp bảo đảm QCNDTTS nhằm thúc đẩy đại đoàn kết dân tộc tỉnh Tuyên Quang;

6. Office of the United Nations High Commissioner for Human Rights (OHCHR) - United Nations, Minority Rights: International Standards and Guidance for Implementation, 2010;

7. Theo kết quả điều tra và thống kê của nhóm đề tài Một số giải pháp bảo đảm quyền của người dân tộc thiểu số nhằm thúc đẩy đại đoàn kết dân tộc tỉnh Tuyên Quang thuộc Sở Khoa học và Công nghệ thực hiện, dựa trên khảo sát 800 phiếu hỏi với người dân tộc thiểu số tại huyện $\mathrm{Na}$ Hang, Hàm Yên, Sơn Dương, khu tái định cư và bệnh viện tại thành phố Tuyên Quang, 2016-2017;

8. Theo kết quả điều tra và thống kê của nhóm đề tài Một số giải pháp bảo đảm quyền của nguời dân tộc thiểu số nhằm thúc đẩy đại đoàn kết dân tộc tỉnh Tuyên Quang thuộc Sở Khoa học và Công nghệ thực hiện, dựa trên khảo sát lại với 160 phiếu hỏi với chính các đối tượng đã được khảo sát lần 1 vào năm 2016-2017 tại huyện Na Hang, Hàm Yên, Sơn Dương, khu tái định cư và bệnh viện tại thành phố Tuyên Quang, 2018;

9. Nguyễn Kim Tường (2017), Giải pháp tổ chức thực hiện một số chuơng trình, chính sách dân tộc trên địa bàn tỉnh Tuyên Quang giai đoạn 2017-2020, Hội thảo lần thứ 2 của Đề tài Một số giải pháp bảo đảm QCNDTTS nhằm thúc đẩy đại đoàn kết dân tộc tỉnh Tuyên Quang. 
The needs of ethnic minority rights in Tuyen Quang province - theory and practice

Do Mac Ngan Doanh

\begin{tabular}{l}
\hline \multicolumn{1}{c}{ Article info } \\
\hline \\
Recieved: \\
28/4/2018 \\
Accepted: \\
12/6/2018 \\
\hline
\end{tabular}

Keywords:

Rights of Ethnic Minorities, Human Rights, like the permissions, the minor people at Tuyên Quang.

\begin{abstract}
Tuyen Quang is highly appreciated in the field of ensuring the effective implementation of ethnic policies and the promotion of national unity. In the direction of integration, Tuyen Quang province has made remarkable effort to contributes to promoting the implementation of the 2013 Vietnamese Constitution and the current Vietnamese law as well as ensuring human rights and citizen rights in the socialist rule of law State. With the general approach of the human rights law, the need for human rights is the core and fundamental content for the beneficiary in a particular geographical area or region.. This article will clarify the specific needs of ethnic minorities in Tuyen Quang, and in order to identify the status of rights and clarifying the rationality of ensuring the rights of ethnic minorities in some populated ethnic minorities.
\end{abstract}

